\title{
Comparing lumbosacral orthosis to routine physical therapy on postural stability in patients with chronic low back pain: A randomized trial
}

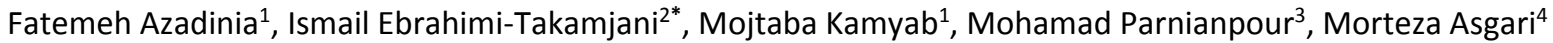

\section{Abstract}

Background: Poor balance performance and impaired postural control have been frequently reported in patients with low back pain. However, postural control is rarely monitored during the course of treatment even though poor postural control may contribute to chronicity and recurrence of symptoms. Therefore, the present study aimed at investigating the effect of a nonextensible lumbosacral orthosis (LSO) versus routine physical therapy on postural stability of patients with nonspecific chronic low back pain.

Methods: This was a randomized controlled trial conducted between November 2015 and May 2016 at the outpatient physical therapy clinic of the School of Rehabilitation Sciences. Patients with nonspecific chronic low back pain aged 20 to 55 years were randomly allocated to the intervention and control groups. Both groups received 8 sessions of physical therapy twice weekly for 4 weeks. The intervention group received nonextensible LSO in addition to routine physical therapy. Pain intensity, functional disability, fear of movement/ (re)injury, and postural stability in 3 levels of postural difficulty were measured before and after 4 weeks of intervention. A $2 \times 2 \times 3$ mixed model of analysis of variance (ANOVA) was used to determine the main and interactive effects of the 3 factors including group, time, and postural difficulty conditions for each variable of postural stability.

Results: The LSO and control groups displayed significant improvement in postural stability at the most difficult postural task conditions (P-value for 95\% area ellipse was 0.003 ; and for phase plane, the mean total velocity and standard deviation of velocity was $<0.001)$. Both groups exhibited a decrease in pain intensity, Oswestry Disability Index, and Tampa Scale of Kinesiophobia after 4 weeks of intervention. A significant difference between groups was found only for functional disability, with greater improvement in the orthosis group $(\mathrm{t}=3.60, \mathrm{P}<0.001)$.

Conclusion: Both routine physical therapy and LSO significantly improved clinical and postural stability outcomes immediately after 4 weeks of intervention. The orthosis group did not display superior outcomes, except for functional disability.

Keywords: Low Back Pain, Orthoses, Postural Control, Center of Pressure, Pain, Functional Disability.

Copyright $\odot$ Iran University of Medical Sciences

Cite this article as: Azadinia F, Ebrahimi-Takamjani I, Kamyab M, Parnianpour M, Asgari M. Comparing lumbosacral orthosis to routine physical therapy on postural stability in patients with chronic low back pain: A randomized trial. Med J Islam Repub Iran. 2017 (1 May); $31: 26$.

https://doi.org/10.18869/mjiri.31.26

\section{Introduction}

Low back pain (LBP) is known as a central factor contributing to physical activity limitation in patients younger than 45 years and is the second most common cause of referral to a physician in this population $(1,2)$.

Poor balance performance and impaired postural control have been frequently observed in patients with LBP (3-5).

Corresponding author:Dr Ismail Ebrahimi-Takamjani, ebrahimi.pt@gmail.com

1. Department of Orthotics and Prosthetics, School of Rehabilitation Sciences, Iran University of Medical Sciences, Tehran, Iran.

2. Department of Physical therapy, School of Rehabilitation Sciences, Iran University of Medical Sciences, Tehran, Iran.

3. Biomechanics Laboratory, Department of Mechanical Engineering, Sharif University of Technology, Tehran, Iran.

4. Department of Mechanical Engineering, Sharif University of technology, Tehran, Iran.
In this population, ample evidence has demonstrated increased postural sway during postural control tasks, poor quality of balance recovery after perturbation, reduced postural strategy variability, and inability to use the hip strategy as a result of restricted lumbopelvic movement (6-13). Various probable causes of impaired postural con-

\footnotetext{
$\uparrow$ What is "already known" in this topic:

Poor balance performance and impaired postural control have been frequently observed in patients with LBP. Impaired postural control may play an important role in chronicity of LBP symptoms.

$\rightarrow$ What this article adds:

Both routine physical therapy and lumbosacral orthosis significantly reduced pain intensity, functional disability and postural sway parameters immediately after 4 weeks of intervention. The orthosis group did not display superior outcomes, except for functional disability.
} 
trol in patients with LBP have been put forth including deterioration of lumbosacral proprioception $(14,15)$, altered central information processing (16), trunk muscle co-contraction (7), and delayed muscle reflex response $(13,17)$.

Given that impaired postural control may play an important role in chronicity of LBP symptoms and can predict the future incidence of LBP (18), it seems that monitoring changes in postural control, as a suitable indicator of whole body performance (19), should be prioritized during the course of treatment. However, most previous studies have focused on improving outcomes such as pain ratings, functional disability, range of motion, muscle strength, and endurance (20-25). Only few clinical trials have assessed the efficacy of treatment at improving postural control $(26,27)$.

One of the most common modalities for conservative management of LBP is lumbosacral orthosis (LSO). Various hypotheses have been proposed to explain the mechanism of action of LSO. Evidence suggests improved proprioception and decreased repositioning error following LSO use (28). Additionally, LSO appears to reduce trunk muscle cocontraction by increasing passive trunk stiffness $(29,30)$. Because both lumbar proprioception disturbance (31) and increased trunk muscle cocontraction $(7,32)$ have been proposed as probable causes of impaired postural control in individuals with LBP, the question that arises is how LSO affects postural control in patients with nonspecific chronic low back pain (CLBP). Therefore, the present study aimed at investigating the effect of a nonextensible LSO versus routine physical therapy on postural stability of patients with nonspecific CLBP. It was hypothesized that routine physical therapy would be less effective than routine physical therapy combined with lumbosacral orthosis in improving postural stability.

\section{Methods}

This was a single-blinded, parallel group randomized controlled trial, with a blinded data analyzer. Assessments, intervention, and data collection were conducted at the outpatient physical therapy clinic of the School of Rehabilitation Sciences in Iran University of Medical Sciences between November 2015 and May 2016. This study was approved by the human ethics committee of Iran University of Medical Sciences (Committee No. 9211503211), and was registered at the Iranian Registry of Clinical Trials with identification number of IRCT2015101523836N2. The estimated sample size was 34 individuals (17 in each group), which was computed via $\mathrm{F}$ test using G-power Software 3.0.1 (Franz Faul, University of Kiel, Kiel, Germany) (33), taking into account, the effect size of 0.25 , power of 0.80 , and $\alpha=0.05$. Allowing for a $25 \%$ dropout rate, 44 patients $(22$ in each group) were recruited.

Patients with nonspecific CLBP were recruited through posters, advertisements, and word of mouth or they were referred by general practitioners. All patients were screened by an experienced physical therapist, prior to entering the study. Inclusion criteria were age 20 to 55 years, a minimum 12-month history of LBP, and at least 1 recurrent episode lasting 1 week during the last 6 months that required treatment or sick leave, or semi-continuous pain. Patients were included if disability score was greater than 6 on the test day. Patients with nonmusculoskeletal LBP, pain spreading down the gluteal fold, neurologic symptoms due to nerve root compression, history of vestibular disorders, neurologic diseases, uncorrectable visual impairments, respiratory diseases, pregnancy, diabetes, history of spinal surgery, inflammatory diseases, and systemic infections, pathologies and severe deformities of spine, lower limb length discrepancy, lower limb musculoskeletal disorders (during the last 6 months), recent physical therapy intervention (mobilization, manipulation, exercise), and history of use of LSO during the last 6 months were excluded from the study. Patients were excluded if they were consuming sedatives and other substances affecting balance or the central nervous system. All participants signed the written informed consent form prior to random allocation.

Before trial commencement, a list of computer generated random numbers between 0 and 1 was provided by a person who was not involved in any stage of the present study. Eligible individuals were allocated to experimental and control groups, using a randomized blocks method with block size of 4 and ratio of 1:1. To conceal allocations, randomization codes were kept in sealed opaque envelopes numbered sequentially. As a result, the responsible researcher (F.A) was unaware of the patient's group allocation until the first session, and the envelopes were opened just prior to the patient's first session. However, due to the manifest nature of orthosis, blinding participants and the outcome assessor was not possible.

\section{Intervention}

Both groups received 8 sessions of routine physical therapy (twice weekly for 4 weeks), which is known as a standard treatment protocol with 8 minutes of ultrasound with $1 \mathrm{MHz}$ frequency and $1.5 \mathrm{w} / \mathrm{cm}^{2}$ intensity and slow circular movements of the transducer head at the paravertebral lower back area; 20 minutes of conventional transcutaneous electrical nerve stimulation (TENS) to the pain region by a dual-channel portable TENS unit with a frequency of 80-100 pulses per second; and 20 minutes of superficial moist heat applied by hot pack. Additionally, stretching exercises to normalize the length of short muscles and general trunk muscle strengthening exercises were prescribed, with no emphasis on trunk stabilizing exercises and no contraction of the transversus abdominis and multifidus muscles. All participants were educated about anatomy and care of lower back. The same experienced and well-trained physical therapist was responsible for the treatment of all patients in both groups throughout the study.

Individuals in the experimental group received nonextensible LSO (QuikDraw Brace, Aspen Medical Products, Inc., Irvine, CA, USA) in addition to routine physical therapy. The same certified orthotist fitted the LSO for all patients according to manufacturer's instructions, tightened the orthosis for all patients with the same tension, and explained to participants how to wear and tighten the 
LSO. Patients were instructed to remember the LSO tension fitted by the orthotist and to continue wearing the LSO with the same tension for 4 consecutive weeks. In addition, they were asked to wear LSO all day except when asleep. To verify that patients were wearing their LSO, they were asked to record the times of donning and doffing of LSO in a daily log.

\section{Measurements}

Primary outcome measures were center of pressure (COP) parameters. Force platform (9260 AA, Kistler, Switzerland) was used to collect COP data along the Xand Y-axes, representing mediolateral (ML) and anteroposterior (AP) directions, respectively. Force plate data were sampled at $100 \mathrm{~Hz}$ frequency and were filtered with second order Butterworth filter with a $10 \mathrm{~Hz}$ cutoff frequency. COP parameters calculated by Matlab software were as follow: area (95\% confidence ellipse), mean total velocity, standard deviation (S.D) of velocity in the AP and ML directions, phase plane portrait in AP-ML (combined), AP, and ML directions. Secondary outcome measures were pain intensity, functional disability, and fear of movement/ (re)injury. Pain intensity was measured using a $10 \mathrm{~cm}$ visual analog scale (VAS), with 2 anchors of 0 and 10, representing "no pain at all" and "worst pain imaginable", respectively. Participants were asked to score their pain intensity on VAS at the test time. Functional disability and fear of movement/(re)injury were measured using the Oswestry disability index (ODI) (34) and the 17 item Tampa Scale of Kinesiophobia (TSK) (35), respectively. All primary and secondary outcome measures were assessed before and after 4 weeks of the intervention. Also, demographic and medical history information were recorded, and all participants filled out the Baecke Physical Activity Questionnaire (36).

\section{Procedure}

Postural sway in quiet standing was measured under the 3 following postural difficulty conditions: standing on force platform with eyes open (rigid-open eyes), standing on force platform with eyes closed (rigid-closed eyes), and standing on foam (foam with $10 \mathrm{~cm}$ thickness and 35 $\mathrm{kg} / \mathrm{m}^{3}$ density overlaying the force platform) with eyes closed (foam-closed eyes). To reduce the effect of learning, individuals were allowed to rehearse each condition twice prior to the actual test. Patients were instructed to stand on the center of the force plate barefoot, with their feet close together and both arms positioned alongside the body. To standardize the position of the feet across all trials, feet positioning was traced on a paper that overlaid the force platform. Each trial lasted 60 seconds during which the individual was asked to relax and breathe normally and remain as still as possible. During the open eye condition, the individual was instructed to stare at a paper on a wall located 4 meters away and at the same level as the patient's eye. A blindfold was used during closed eye conditions. Data recording was started 5 seconds after the patient was able to maintain relevant posture on the force platform. The sequence of different postural task conditions was selected randomly and each postural task condition was repeated 3 times, with 1 minute of rest between trials.

\section{Statistical Analysis}

Data were analyzed using SPSS software Version 16.0. To minimize bias, all data were coded and the statistician was kept blind to group allocation. The average of 3 records was used for each postural stability variables in each postural task condition. The statistical significance level was set at $\mathrm{p}<0.05$.

Normality of distribution of all variables was assessed by the kolmogorov-Simonov (K-S) test. Mann-Whitney U test was used to compare pain intensity between groups on the test day. The Chi-square test was used to compare sex distribution between groups. Independent sample $t$ test was used to compare other demographic and baseline clinical characteristics between groups.

A $2 \times 2 \times 3$ mixed model of analysis of variance (ANOVA) was used to determine the main and interactive effects of 3 factors including group (experiment and control), time (before and after intervention), and postural difficulty conditions (rigid-open eyes, rigid-closed eyes, and foam-closed eyes) for each variable of postural stability. Paired-samples t test was used for post hoc pairwise comparisons; and for multiple comparisons, Bonferroni corrections were made. A paired sample t test was used to determine the effectiveness of treatment for each group in pain intensity, ODI, and TSK. Furthermore, an independent $t$ test was used to compare the LSO and control groups for above-mentioned clinical variables.

\section{Results}

Between November 2015 and May 2016, 102 patients (68 females and 34 males) were screened. Of them, 58 patients were excluded because they did not meet the inclusion criteria $(n=49)$, or because they declined to participate $(\mathrm{n}=9)$. Of the 44 patients, 2 from the LSO group ( 1 male and 1 female) and 1 from the control group dropped out due to disease (1 patient) or unwillingness to be referred for postural stability reassessment ( 2 patients), despite having completed the intervention period. Therefore, data from these 3 patients were not included in the analysis (Fig. 1).

Comparison of baseline clinical characteristics and postural stability variables between the 2 groups showed no significant difference prior to the start of the intervention (Table 1).

As shown in Figure 2, pain intensity, ODI, and TSK reduced significantly in both groups after 4 weeks of intervention $(\mathrm{p}<0.001)$. The LSO group showed a greater decrease in pain and disability than the control group although this decrease was significant only for disability $(\mathrm{t}=$ $3.60, \mathrm{p}<0.001)$. 


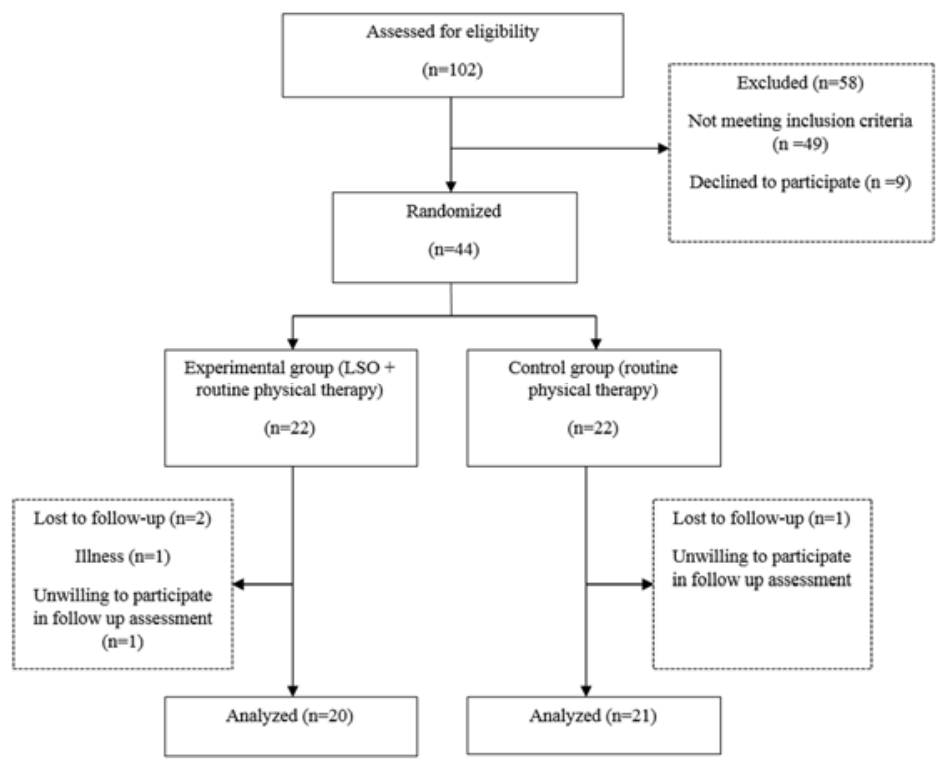

Fig. 1. Flow diagram of participant screening, allocation, and assessment.

Mean and standard deviation values for all postural stability variables, also changes in postural stability variables with $95 \%$ confidence interval (CI) for both the LSO and control groups, are presented in Table 2. As demonstrated in Table 3, there was a significant main effect of time (before and after intervention) and postural task difficulty on all COP parameters. A significant interaction of time with postural task difficulty was detected for all COP parameters. However, the main effect of group (LSO versus control) was not significant. The results of post hoc analysis revealed a significant improvement of postural stability at the most challenging postural task conditions (foam surface- closed eyes $)(\mathrm{p}<0.05)$.

\section{Discussion}

Previous studies have demonstrated that postural control is impaired in individuals having nonspecific CLBP (3-5). However, postural control is rarely monitored during the course of treatment for nonspecific CLBP even though poor postural control may contribute to chronicity and recurrence of symptoms. Therefore, the present study aimed at evaluating the effect of LSO, one of the most common treatments prescribed for the conservative management of low back pain, versus routine physical therapy, on the postural stability of patients with nonspecific CLBP. Both the LSO and control groups displayed significant improvement in postural stability at the most

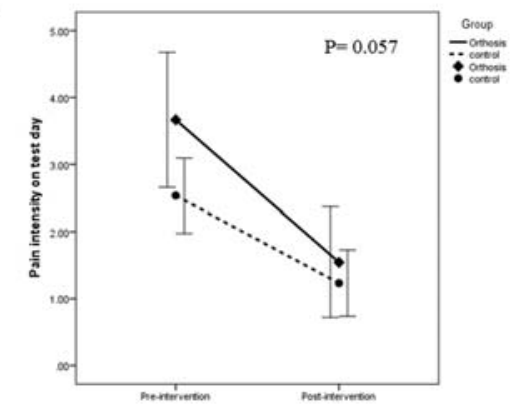

B

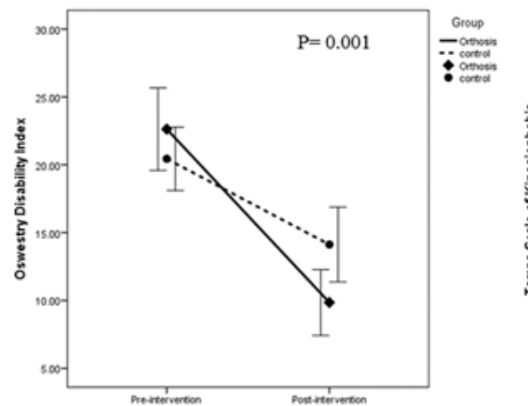

C

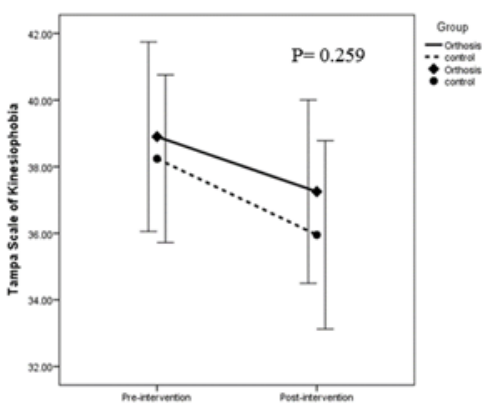

Fig. 2. Mean and 95\% confidence intervals for both orthosis and control groups. (A): pain intensity on test day (VAS) before and after intervention, (B) Oswestry Disability Index before and after intervention, (C) Tampa Scale of Kinesiophobia before and after intervention. P-values are related to the difference between groups. 
Table 1. Baseline demographic and clinical characteristics of patients in the orthosis and control groups

\begin{tabular}{lccc} 
& $\begin{array}{c}\text { Orthosis Group }(\mathrm{n}=20) \\
\text { Mean } \pm \text { SD }\end{array}$ & $\begin{array}{c}\text { Control Group }(\mathrm{n}=21) \\
\text { Mean } \pm \text { SD }\end{array}$ & $P$ value \\
\hline Sex (Male/Female) & $8 / 12$ & $7 / 14$ & 0.65 \\
Age (year) & $27.3 \pm 5.3$ & $27 \pm 5.3$ & 0.8 \\
Height $(\mathrm{cm})$ & $170.3 \pm 10.5$ & $169.9 \pm 8.7$ & 0.79 \\
Weight $(\mathrm{kg})$ & $66.8 \pm 13.3$ & $64.6 \pm 11.4$ & 0.57 \\
LBP duration (year) & $4.31 \pm 3.21$ & $5.7 \pm 4.58$ & 0.27 \\
Pain intensity on test day (/10) & $3.66 \pm 2.15$ & $2.53 \pm 1.22$ & 0.1 \\
ODI (\%) & $22.63 \pm 6.49$ & $20.44 \pm 5.12$ & 0.23 \\
TSK (17-68) & $38.9 \pm 6.07$ & $38.23 \pm 5.53$ & 0.71 \\
Physical activity & $7.5 \pm 1.32$ & $7.96 \pm 1.37$ & 0.27 \\
\hline Pain intensity was according to 10 cm visual analog scale; ODI= Oswestry Disability Index; TSK= Tampa Scale of Kinesiophobia; SD= Standard Deviation
\end{tabular}

difficult postural task conditions (foam-closed eyes). However, the LSO group displayed significantly greater improvement in functional disability, while no significant difference between groups was found for the other outcome measures assessed.

The results described above are consistent with those obtained in the study by Salavati et al. (27) that demonstrated that postural control improved significantly for both the stabilization exercise and routine physical therapy groups after 4 weeks of intervention. At least, a part of the improved postural stability appears to be attributed to improved pain (37). Nociceptive afferents are proven to cause changes in muscle spindle discharge and subsequently impair proprioception (3). The ability to detect body position probably improves with reduction of pain and better proprioception, which in turn may result in reduced postural sway. In line with these results, Ruhe et al. (37) attributed the impairment of postural stability to pain interference and demonstrated decreased postural sway with reduced pain regardless of intervention type. The results obtained by Ruhe et al., in another study (10) and by Corbeil et al. (38) support the hypothesis of a direct relationship between pain intensity and postural sway.
However, many studies have declared that pain interference cannot be responsible for the changes in postural control in nonspecific CLBP patients; rather, these changes probably result from the adoption of a protective postural strategy by patients (39). This strategy is muscle cocontraction and indicates individual's efforts to increase spinal stability, but it may inadvertently impair postural control via increased muscle force variability and increased noise due to the involvement of additional motor units (32). Therefore, it seems conceivable to expect that decreased muscle cocontraction led to improvement in postural stability. Whether general trunk exercises prescribed as part of routine physical therapy can alter trunk muscle activity pattern in patients with nonspecific CLBP is debatable.

Another probable explanation for our finding is that increased endurance of the lumbar extensor muscles via an effect on trunk muscle fatigue led to reduced postural sway in both groups. Previous studies have reported increased postural sway due to lumbar extensor fatigue (40). Trunk muscle fatigue may increase postural sway by reducing proprioception (15) and increasing muscle force output variability (41). Because the postural control sys-

Table 2. Mean \pm SD of COP Parameters, changes in postural stability variables "before to after the intervention" ( $95 \%$ confidence interval) in different postural task conditions for LSO and control groups

\begin{tabular}{|c|c|c|c|c|c|c|c|}
\hline \multirow{2}{*}{\multicolumn{2}{|c|}{$\begin{array}{l}\text { Postural conditions and cop } \\
\text { parameters }\end{array}$}} & \multicolumn{2}{|c|}{ Before the intervention } & \multicolumn{2}{|c|}{ After the intervention } & \multirow{2}{*}{$\begin{array}{l}\text { Before to after } \\
\text { intervention }(95 \% \\
\text { confidence interval) } \\
\text { LSO }(n=20)\end{array}$} & \multirow{2}{*}{$\begin{array}{l}\text { Before to after interven- } \\
\text { tion }(95 \% \text { confidence } \\
\text { interval) } \\
\text { Control }(n=21)\end{array}$} \\
\hline & & $\operatorname{LSO}(n=20)$ & Control $(\mathrm{n}=21)$ & $\operatorname{LSO}(\mathrm{n}=20)$ & Control $(n=21)$ & & \\
\hline \multicolumn{8}{|c|}{ Rigid surface-open eyes } \\
\hline $95 \%$ area ellipse & & $4.74 \pm 2.38$ & $4.55 \pm 1.78$ & $4.55 \pm 2.59$ & $4.29 \pm 2.31$ & $0.18(-0.31-0.69)$ & $0.25(-0.32-0.84)$ \\
\hline \multirow[t]{3}{*}{ Phase plane portrait } & (AP-ML) & $1.5 \pm 0.38$ & $1.48 \pm 0.25$ & $1.44 \pm 0.36$ & $1.44 \pm 0.25$ & $0.56(-0.06-0.17)$ & $0.04(-0.02-0.1)$ \\
\hline & $\mathrm{AP}$ & $0.98 \pm 0.23$ & $0.94 \pm 0.17$ & $0.94 \pm 0.24$ & $0.92 \pm 0.18$ & $0.03(-0.02-0.09)$ & $0.02(-0.02-0.08)$ \\
\hline & ML & $1.12 \pm 0.32$ & $1.13 \pm 0.20$ & $1.08 \pm 0.28$ & $1.1 \pm 0.2$ & $0.04(-0.06-0.15)$ & $0.03(-0.02-0.08)$ \\
\hline Mean total velocity & & $0.99 \pm 0.28$ & $0.98 \pm 0.18$ & $0.95 \pm 0.24$ & $0.95 \pm 0.17$ & $0.03(-0.05-0.12)$ & $0.02(-0.01-0.07)$ \\
\hline \multirow[t]{2}{*}{ S.D velocity } & AP & $0.84 \pm 0.21$ & $0.81 \pm 0.16$ & $0.81 \pm 0.2$ & $0.79 \pm 0.15$ & $0.03(-0.03-0.1)$ & $0.01(-0.03-0.07)$ \\
\hline & ML & $0.99 \pm 0.31$ & $1 \pm 0.2$ & $0.96 \pm 0.27$ & $0.97 \pm 0.18$ & $0.03(-0.07-0.13)$ & $0.03(-0.01-0.08)$ \\
\hline \multicolumn{8}{|c|}{ Rigid surface-closed eyes } \\
\hline $95 \%$ area ellipse & & $6.53 \pm 3.58$ & $6 \pm 2.9$ & $5.86 \pm 3.55$ & $6.01 \pm 4.64$ & $0.67(-0.20-1.55)$ & $-0.01(-1.15-1.13)$ \\
\hline \multirow[t]{3}{*}{ Phase plane portrait } & (AP-ML) & $2.02 \pm 0.55$ & $2.03 \pm 0.52$ & $1.91 \pm 0.53$ & $1.94 \pm 0.5$ & $0.1(-0.01-0.22)$ & $0.09(-0.01-0.19)$ \\
\hline & $\mathrm{AP}$ & $1.28 \pm 0.30$ & $1.28 \pm 0.30$ & $1.22 \pm 0.32$ & $1.20 \pm 0.3$ & $0.05(-0.02-0.13)$ & $0.07(0.01-0.13)$ \\
\hline & ML & $1.55 \pm 0.48$ & $1.57 \pm 0.45$ & $1.45 \pm 0.45$ & $1.51 \pm 0.41$ & $0.09(-0.003-0.18)$ & $0.05(-0.04-0.15)$ \\
\hline Mean total velocity & & $1.37 \pm 0.38$ & $1.38 \pm 0.38$ & $1.31 \pm 0.37$ & $1.32 \pm 0.33$ & $0.06(-0.02-0.15)$ & $0.06(-0.008-0.14)$ \\
\hline \multirow[t]{2}{*}{ Sd velocity } & AP & $1.15 \pm 0.29$ & $1.15 \pm 0.28$ & $1.11 \pm 0.29$ & $1.08 \pm 0.26$ & $0.03(-0.03-0.11)$ & $0.06(0.0008-0.12)$ \\
\hline & ML & $1.42 \pm 0.44$ & $1.46 \pm 0.44$ & $1.33 \pm 0.42$ & $1.39 \pm 0.4$ & $0.09(-0.01-0.19)$ & $0.06(-0.03-0.16)$ \\
\hline \multicolumn{8}{|c|}{ Foam surface-closed eyes } \\
\hline $95 \%$ area ellipse & & $21.91 \pm 9.65$ & $18.67 \pm 5.09$ & $18.83 \pm 7.71$ & $17.13 \pm 5.7$ & $3.07(0.42-5.72)$ & $1.53(-0.07-3.15)$ \\
\hline \multirow[t]{3}{*}{ Phase plane portrait } & (AP-ML) & $4.51 \pm 0.98$ & $4.44 \pm 0.89$ & $3.93 \pm 0.63$ & $4.12 \pm 0.71$ & $0.57(0.27-0.88)$ & $0.32(0.11-0.54)$ \\
\hline & $\mathrm{AP}$ & $3.05 \pm 0.64$ & $2.94 \pm 0.51$ & $2.65 \pm 0.41$ & $2.67 \pm 0.38$ & $0.39(0.19-0.6)$ & $0.26(0.12-0.39)$ \\
\hline & ML & $3.30 \pm 0.77$ & $3.32 \pm 0.77$ & $2.89 \pm 0.51$ & $3.11 \pm 0.64$ & $0.41(0.15-0.67)$ & $0.2(0.02-0.39)$ \\
\hline Mean total velocity & & $3.20 \pm 0.72$ & $3.17 \pm 0.66$ & $2.76 \pm 0.44$ & $2.92 \pm 0.53$ & $0.43(0.2-0.66)$ & $0.25(0.08-0.41)$ \\
\hline \multirow[t]{2}{*}{ SD velocity } & $\mathrm{AP}$ & $2.85 \pm 0.64$ & $2.75 \pm 0.51$ & $2.44 \pm 0.39$ & $2.5 \pm 0.38$ & $0.4(0.2-0.59)$ & $0.25(0.11-0.39)$ \\
\hline & ML & $3.13 \pm 0.75$ & $3.17 \pm 0.77$ & $2.72 \pm 0.48$ & $2.96 \pm 0.65$ & $0.4(0.15-0.66)$ & $0.21(0.02-0.39)$ \\
\hline
\end{tabular}




\begin{tabular}{|c|c|c|c|c|c|c|c|c|c|c|c|c|c|c|}
\hline \multirow{2}{*}{$\begin{array}{l}\text { Independent } \\
\text { variable }\end{array}$} & \multicolumn{2}{|c|}{$95 \%$ area ellipse } & \multicolumn{2}{|c|}{$\begin{array}{c}\text { Phase plane } \\
\text { portrait (AP-ML) }\end{array}$} & \multicolumn{2}{|c|}{$\begin{array}{l}\text { Phase plane } \\
\text { portrait (AP) }\end{array}$} & \multicolumn{2}{|c|}{$\begin{array}{l}\text { Phase plane } \\
\text { portrait (ML) }\end{array}$} & \multicolumn{2}{|c|}{$\begin{array}{l}\text { Mean total } \\
\text { velocity }\end{array}$} & \multicolumn{2}{|c|}{ SD Velocity (AP) } & \multicolumn{2}{|c|}{ SD Velocity (ML) } \\
\hline & F ratio & $P$ & F ratio & $P$ & F ratio & $P$ & $\mathrm{~F}$ ratio & $P$ & F ratio & $P$ & F ratio & $P$ & $F$ ratio & $P$ \\
\hline Group & 0.615 & 0.438 & 0.026 & 0.87 & 0.1 & 0.74 & 0.20 & 0.65 & 0.03 & 0.84 & 0.05 & 0.82 & 0.29 & 0.59 \\
\hline Time & 7.74 & $0.008^{*}$ & 22.22 & $<0.001^{*}$ & 28.9 & $<0.001^{*}$ & 14.49 & $<0.001^{*}$ & 21.71 & $<0.001^{*}$ & 26.28 & $<0.001^{*}$ & 13.93 & $0.001^{*}$ \\
\hline $\begin{array}{l}\text { Postural task } \\
\text { difficulty }\end{array}$ & 290.98 & $<0.001^{*}$ & 735.2 & $<0.001^{*}$ & 780.16 & $<0.001^{*}$ & 577.69 & $<0.001^{*}$ & 742.15 & $<0.001^{*}$ & 767.3 & $<0.001^{*}$ & 564.4 & $<0.001^{*}$ \\
\hline $\begin{array}{l}\text { Group } \times \\
\text { Time }\end{array}$ & 1.09 & 0.3 & 1.19 & 0.28 & 0.598 & 0.44 & 1.37 & 0.24 & 0.99 & 0.32 & 0.77 & 0.38 & 0.96 & 0.33 \\
\hline $\begin{array}{l}\text { Group } \times \\
\text { postural task } \\
\text { difficulty }\end{array}$ & 1.92 & 0.17 & 0.1 & 0.8 & 0.07 & 0.83 & 0.38 & 0.59 & 0.19 & 0.71 & 0.00 & 0.95 & 0.51 & 0.51 \\
\hline $\begin{array}{l}\text { Time } \times \\
\text { postural task } \\
\text { difficulty }\end{array}$ & 8.04 & $0.003^{*}$ & 20.15 & $<0.001^{*}$ & 24.74 & $<0.001^{*}$ & 12.75 & $<0.001^{*}$ & 20.59 & $<0.001^{*}$ & 25.36 & $<0.001^{*}$ & 12.93 & $<0.001^{*}$ \\
\hline $\begin{array}{l}\text { Group } \times \\
\text { time } \times \\
\text { postural task } \\
\text { difficulty }\end{array}$ & 0.94 & 0.36 & 1.91 & 0.17 & 1.7 & 0.198 & 1.59 & 0.21 & 1.9 & 0.172 & 1.88 & 0.17 & 1.72 & 0.19 \\
\hline
\end{tabular}

tem requires sensory and motor system cooperation for optimal function (19), alteration of each of these components may affect postural stability. Thus, theoretically, it is conceivable that reduced trunk muscle fatigue improved postural stability. In this context, the slightly better postural stability outcome in the LSO group can be attributed to the LSO's capability to decrease trunk muscle activity below the threshold of 5\% maximum voluntary contraction (MVA), preventing muscle fatigue during daily activities. This assumption can be confirmed by greater improvement in functional capacity in the LSO group than in the control group. However, none of the mentioned hypotheses was investigated in the present study and the explanations presented here are only based on scientific speculations.

A number of previous studies have investigated the effect of LSO on postural stability. Munoz et al. (42) observed a $37 \%$ reduction in COP displacement and improved postural control following LSO use in patients with herniated discs. Due to differences in study design, type of orthosis, and duration of intervention (immediate effect in their study versus 4 weeks of intervention in the present study), the results described above and our own should be compared with caution. In another study, Munoz et al. (43) revealed that the effectiveness of orthosis can vary from detrimental to beneficial, depending on the postural task difficulty and degree of lumbar lordosis provided by the orthosis. The findings of that study demonstrated that orthosis was futile at the easiest postural task level and was detrimental to postural stability at the most difficult postural task level. However, the outcomes of the present study cannot be directly compared with those of Munoz et al. (43) due to differences in participants' health status (healthy in their study versus CLBP in this study), postural task (sitting position versus quiet standing position in the present study), study design, and the duration of intervention.

The present study, as well as previous reports by Salavati et al. (27), and Ruhe et al. (37), demonstrated that postural stability improved when assessed immediately after intervention, but whether this improvement can be maintained in the long-term is unclear. Leinonen et al.
(44) observed patients over a longer period of follow-up and did not find a sustained improvement in postural stability.

In LSO group functional disability was reduced to a greater extent than in the control group. This outcome is consistent with that of Morrisette et al. (21) and kawchuk et al. (20), and may be related to LSO's capability to reduce trunk muscle cocontraction (21). Because LSO can augment passive trunk stiffness, it can reduce trunk muscle activity below 5\% MVA (30). Thus, it can avoid trunk muscle fatigue and related pain and lead to greater improvement in function.

This study has some strength. The present study was the first randomized clinical trial to investigate the efficacy of LSO on postural stability in patients with nonspecific chronic low back pain. The previous studies by Munoz et al., (42, 43) were laboratory- based experimental studies that investigated immediate effect of a specific kind of LSO (Lordactive orthosis) on healthy patients (12 subjects)(43), or on discopathy suffers (11 individuals) (42).

\section{Limitations}

The present study had several limitations. First, due to the manifest nature of orthosis, blinding participants and assessors was not possible although participants were blind to outcome measures. Additionally, bias in statistical analysis was prevented through coding data and blinding the statistician. Second, for more accurate assessment of LSO effects, it was better to compare the experimental group with a control group receiving no intervention but depriving the control group of the routine physiotherapy treatment in this study was impossible because of ethical issues. Third, whether the patients wore the orthosis according to the instructions was questionable. However, all patients were asked to record daily times of putting on and removal of the orthosis to allow the researchers to supervise compliance. Finally, because of participant characteristics such as young age, mild to moderate functional disability, and short duration back pain, caution should be taken when generalizing these findings to older patients with more severe disability and longer duration of back pain. 


\section{Conclusion}

The present study revealed that both LSO and routine physical therapy improve postural control outcomes after 4 weeks of intervention, with no statistical difference between the interventions. We also observed slightly greater but not significant improvement in favor of the LSO group for pain intensity. Furthermore, in the LSO group, functional disability was reduced to a greater extent than in the control group.

\section{Acknowledgments}

Iran University of Medical Sciences [Grant No. 1334] supported this study. We would like to thank Aspen Medical Products, Inc., Irvine, CA, USA, for donating the lumbosacral orthoses.

Conflict of Interests: The authors declared no potential conflict of interest with respect to the research, authorship, and/or publication of this article.

\section{References}

1. Mazaheri M, Coenen P, Parnianpour M, Kiers H, van Dieën JH. Low back pain and postural sway during quiet standing with and without sensory manipulation: a systematic review. Gait Postur. 2013;37(1):12-22.

2. Krismer M, Van Tulder M. Low back pain (non-specific). Best Pract Res Clin Rheumatol. 2007;21(1):77-91.

3. Ruhe A, Fejer R, Walker B. Center of pressure excursion as a measure of balance performance in patients with non-specific low back pain compared to healthy controls: a systematic review of the literature. Eur Spine J. 2011;20(3):358-68.

4. Yahia A, Jribi S, Ghroubi S, Elleuch M, Baklouti S, Elleuch MH. Evaluation of the posture and muscular strength of the trunk and inferior members of patients with chronic lumbar pain. Joint Bone Spine. 2011;78(3):291-7.

5. Schelldorfer S, Ernst MJ, Rast FM, Bauer CM, Meichtry A, Kool J. Low back pain and postural control, effects of task difficulty on centre of pressure and spinal kinematics. Gait Postur. 2015;41(1):112-8.

6. Mok NW, Brauer SG, Hodges PW. Postural recovery following voluntary arm movement is impaired in people with chronic low back pain. Gait Postur. 2011;34(1):97-102.

7. Mok NW, Brauer SG, Hodges PW. Failure to use movement in postural strategies leads to increased spinal displacement in low back pain. Spine. 2007;32(19):E537-E43.

8. Brumagne S, Janssens L, Janssens E, Goddyn L. Altered postural control in anticipation of postural instability in persons with recurrent low back pain. Gait Postur. 2008;28(4):657-62.

9. Brumagne S, Janssens L, Knapen S, Claeys K, Suuden-Johanson E. Persons with recurrent low back pain exhibit a rigid postural control strategy. Eur Spine J. 2008;17(9):1177-84.

10. Ruhe A, Fejer R, Walker B. Is there a relationship between pain intensity and postural sway in patients with non-specific low back pain? BMC Musculoskel Dis. 2011;12:162.

11. Jones SL, Henry SM, Raasch CC, Hitt JR, Bunn JY. Individuals with non-specific low back pain use a trunk stiffening strategy to maintain upright posture. J Electromyograph Kinesiol. 2012;22(1):13-20.

12. Van Daele U, Hagman F, Truijen S, Vorlat P, Van Gheluwe B, Vaes $P$. Differences in balance strategies between nonspecific chronic low back pain patients and healthy control subjects during unstable sitting. Spine. 2009;34(11):1233-8.

13. van Dieën JH, Koppes LL, Twisk JW. Low back pain history and postural sway in unstable sitting. Spine. 2010;35(7):812-7.

14. O'Sullivan PB, Burnett A, Floyd AN, Gadsdon K, Logiudice J, Miller $\mathrm{D}$, et al. Lumbar repositioning deficit in a specific low back pain population. Spine. 2003;28(10):1074-9.

15. Johanson E, Brumagne S, Janssens L, Pijnenburg M, Claeys K, Pääsuke M. The effect of acute back muscle fatigue on postural control strategy in people with and without recurrent low back pain. Eur
Spine J. 2011;20(12):2152-9.

16. Wand BM, Di Pietro F, George P, O'Connell NE. Tactile thresholds are preserved yet complex sensory function is impaired over the lumbar spine of chronic non-specific low back pain patients: a preliminary investigation. Physiotherapy. 2010;96(4):317-23.

17. Reeves NP, Cholewicki J, Narendra KS. Effects of reflex delays on postural control during unstable seated balance. J Biomech. 2009;42(2):164-70.

18. Hodges PW, Tucker K. Moving differently in pain: a new theory to explain the adaptation to pain. Pain. 2011;152(3):S90-S8.

19. Leitner C, Mair P, Paul B, Wick F, Mittermaier C, Sycha T, et al. Reliability of posturographic measurements in the assessment of impaired sensorimotor function in chronic low back pain. J Electromyograph Kinesiol. 2009;19(3):380-90.

20. Kawchuk GN, Edgecombe TL, Wong AYL, Cojocaru A, Prasad N. A non-randomized clinical trial to assess the impact of nonrigid, inelastic corsets on spine function in low back pain participants and asymptomatic controls. Spine J. 2015;15(10):2222-7.

21. Morrisette DC, Cholewicki J, Patenge WF, Logan S, Seif G, McGowan S. A randomized clinical trial comparing extensible and inextensible lumbosacral orthoses and standard care alone in the management of lower back pain. Spine. 2014;39(21):1733.

22. Koumantakis GA, Watson PJ, Oldham JA. Supplementation of general endurance exercise with stabilisation training versus general exercise only: physiological and functional outcomes of a randomised controlled trial of patients with recurrent low back pain. Clin Biomech. 2005;20(5):474-82.

23. Kasai R. Current trends in exercise management for chronic low back pain: comparison between strengthening exercise and spinal segmental stabilization exercise. J Physic Ther Sci. 2006;18(1):97105 .

24. Utter A, Anderson ML, Cunniff JG, Kaufman KR, Jelsing EJ, Patrick TA, et al. Video fluoroscopic analysis of the effects of three commonly-prescribed off-the-shelf orthoses on vertebral motion. Spine. 2010;35(12):E525-E9.

25. Niemistö L, Rissanen P, Sarna S, Lahtinen-Suopanki T, Lindgren K-A, Hurri H. Cost-effectiveness of combined manipulation, stabilizing exercises, and physician consultation compared to physician consultation alone for chronic low back pain: a prospective randomized trial with 2-year follow-up. Spine. 2005;30(10):1109-15.

26. Mehling WE, Hamel KA, Acree M, Byl N, Hecht FM. Randomized, controlled trial of breath therapy for patients with chronic low-back pain. Alt Ther Health Med. 2005;11(4):44.

27. Salavati M, Akhbari B, Takamjani IE, Bagheri H, Ezzati K, Kahlaee AH. Effect of spinal stabilization exercise on dynamic postural control and visual dependency in subjects with chronic non-specific low back pain. J Bodywork Mov Ther. 2016;20(2):441-8.

28. Cholewicki J, Shah KR, McGill KC. The effects of a 3-week use of lumbosacral orthoses on proprioception in the lumbar spine. J Orth Sport Physic Ther. 2006;36(4):225-31.

29. Cholewicki J, McGill KC, Shah KR, Lee AS. The effects of a threeweek use of lumbosacral orthoses on trunk muscle activity and on the muscular response to trunk perturbations. BMC Musculoskelet Dis. 2010;11(1): 1 .

30. Cholewicki J, Reeves NP, Everding VQ, Morrisette DC. Lumbosacral orthoses reduce trunk muscle activity in a postural control task. J Biomech. 2007;40(8):1731-6.

31. Brumagne S, Cordo P, Verschueren S. Proprioceptive weighting changes in persons with low back pain and elderly persons during upright standing. Neurosci Let. 2004;366(1):63-6.

32. Reeves NP, Everding VQ, Cholewicki J, Morrisette DC. The effects of trunk stiffness on postural control during unstable seated balance. Experiment Brain Res. 2006;174(4):694-700.

33. Faul F, Erdfelder E, Lang A-G, Buchner A. G* Power 3: A flexible statistical power analysis program for the social, behavioral, and biomedical sciences. Behav Res Method. 2007;39(2):175-91.

34. Mousavi SJ, Parnianpour M, Mehdian H, Montazeri A, Mobini B. The Oswestry disability index, the Roland-Morris disability questionnaire, and the Quebec back pain disability scale: translation and validation studies of the Iranian versions. Spine. 2006;31(14):E454-E9.

35. Jafari H, Ebrahimi I, Salavati M, Kamali M, Fata L. Psychometric properties of Iranian version of Tampa Scale for Kinesiophobia in low back pain patients. J Rehab. 2010;11(1):23-30.

36. Sadeghisani M, Manshadi FD, Azimi H, Montazeri A. Validity and Reliability of the Persian Version of Baecke Habitual Physical Activi- 
ty Questionnaire in Healthy Subjects. Asian J Sport Med. 2016 (inpress).

37. Ruhe A, Fejer R, Walker B. Pain relief is associated with decreasing postural sway in patients with non-specific low back pain. BMC Musculoskelet Dis. 2012;13(1):1.

38. Corbeil P, Blouin J-S, Teasdale N. Effects of intensity and locus of painful stimulation on postural stability. Pain. 2004;108(1):43-50.

39. Moseley GL, Hodges PW. Are the changes in postural control associated with low back pain caused by pain interference? Clin J Pain. 2005;21(4):323-9.

40. Davidson BS, Madigan ML, Nussbaum MA. Effects of lumbar extensor fatigue and fatigue rate on postural sway. Eur J Appl Physiolog. 2004;93(1-2):183-9.

41. Ng JK-F, Parnianpour M, Richardson CA, Kippers V. Effect of fatigue on torque output and electromyographic measures of trunk muscles during isometric axial rotation. Arch Physic Med Rehab. 2003;84(3):374-81.

42. Munoz F, Salmochi J-F, Faouen P, Rougier P. Low back pain sufferers: Is standing postural balance facilitated by a lordotic lumbar brace? Ortho Traumat Surg Res. 2010;96(4):362-6.

43. Munoz F, Rouboa A, Rougier P. The balance control effects on sitting posture induced by lumbosacral orthosis wear vary depending on the level of stability. Appl Ergonom. 2013;44(4):511-6.

44. Leinonen V, Kankaanpaa M, Luukkonen M, Kansanen M, Hanninen $\mathrm{O}$, Airaksinen $\mathrm{O}$, et al. Lumbar paraspinal muscle function, perception of lumbar position, and postural control in disc herniationrelated back pain. Spine-Philadelphia-Harper and row publishers then JB Lippincott company then lippencott Williams and Wilkins. 2003;28(8):842-8. 